\title{
Los ingenieros urbanistas en la España decimonónica
}

\author{
María Dolores Antigüedad del Castillo-Olivares*
}

\begin{abstract}
RESUMEN ABSTRACT
Los Ingenieros de Caminos actúan en España como urbanistas en la segunda mitad del siglo xix. Son un nuevo cuerpo de funcionarios a las órdenes de la politica progresista del gobierno en materia urbana. Poseian deseos de renovación, interés por los avances técnicos y sentido práctico, además de una formación científica. Su trabajo se refleja en los proyectos de ensanche de poblaciones realizados bajo nuevos supuestos que tratan de hacer frente a las necesidades de la naciente ciudad industrial.

Civil engineers operated as town planners in the second half of the nineteenth Century. They were a new functionary corps who was under the orders of the progressive policy of the gobernment in urban matters. They had wishes for renewal, interest in technichal improvements and practical sense, besides a scientific training. Their work is reflected in their projects in town extensions which they designed under new assumptions that try to face up to the needs of the rising industrial city.
\end{abstract}

\section{LOS INGENIEROS URBANISTAS EN LA ESPAÑA DECIMONÓNICA}

Fue en la segunda mitad del siglo XIX cuando se produjeron los mayores cambios en los trazados urbanos de las ciudades españolas, bien por reformas interiores, bien por la construcción de ensanches. En estos fe-

\footnotetext{
* Departamento de Historia del Arte. UNED.
} 
nómenos nuevos va a desempeñar un importante papel el ingeniero civil, elevado a la categoría de urbanista, función que asumirá hasta fines de siglo, y que contiene elementos peculiares sobre los que es interesante reflexionar.

Un Real Decreto de 30 de abril de 1835 establece definitivamente el Cuerpo de Ingenieros Civiles, funcionarios del Estado que asumian genéricamente la tarea de las obras públicas. Este decreto venía a cerrar un largo camino desde que, en el siglo xVIII, Agustín de Betancourt defendiera la necesidad de crear un cuerpo de funcionarios con la adecuada formación científica y técnica que les permitiera acometer la labor de construir los caminos y las obras públicas del reino ${ }^{1}$.

Desde ese momento los ingenieros civiles se convirtieron en un grupo de funcionarios adecuadamente preparados; de su Escuela salió en 1839 la primera promoción que asumió la nueva política liberal en las obras públicas del gobierno de Isabel II.

\section{LA DEFENSA DE COMPETENCIAS}

Frente a esta nueva clase de ingenieros, los arquitectos aparecían como profesionales con una formación académica insuficiente y un conocimiento escaso respecto a las obras públicas entonces en marcha? La existencia de un cuerpo funcionarial ocupado de los encargos públicos de mayor relevancia los relegaba casi exclusivamente a las promociones privadas, sin el volumen ni la importancia de las obras públicas. El Real Decreto de 10 de octubre de 1845, «llustración para promover y ejecutar las Obras Públicas», trató de deslindar las competencias de unos y otros sin conseguir acallar las protestas de los arquitectos; la situación obligó al Gobierno, en 1846, a la publicación de una nueva

La historia del Cuerpo de Ingenieros desde el siglo xvill hasta su establecimiento en 1835 está perfectamente expuesta en el texto de Antonio Rumeu df AHMAs: Ciencia y Tecnologia en la España llustrada. La Escuela de Caminos, Canales y Puertos. Madrid, Colegio de Ingenieros de Caminos, Canales y Puertos y Ed. Turner, 1980. En la página 61 se recoge el informe de Betancourt al Conde de Floridablanca el 20 de julio de 1791 con las cualidades que debia poseer un di. rector de caminos, calidad que se podia reconocer en Carlos Le Maur artífice de los caminos de Guadarrama y Sierra Morena

En 1829 José Agustín de Larramendi fue encargado de reorganizar el cuerpo y los estudios de !ngenieria, en su memoria justificativa apelaba a lo negativo de la intervención de ingenieros militares y arquitectos en el plan de obras públicas porque "ni unos ni otros estarian preparados adecuadamente para este fin, los segundos por carecer de los conocimientos precisos". RUMF $U$ DE ARMAS: Op. cit. pág. 423 
delimitación de competencias mediante el Real Decreto de 25 de noviembre.

La rectificación reservaba a los arquitectos la construcción de cárceles que con anterioridad, como edificio público, podían levantar los ingenieros; también podían construir caminos, puentes y canales siempre que fueran de promoción privada. Los ingenieros quedaban competentes para las obras que les eran propias como puentes, puertos, presas, canales, faros etc., pero también, y ello es fundamental para el tema que nos ocupa, para realizar los trazados de anteproyectos de ensanches de las ciudades ${ }^{3}$. Así, pues, los ingenieros se convertían en instrumentos al servicio del Estado, abanderado de la idea de progreso en la escena urbana y promotor de las iniciativas más importantes en la evolución hacia la ciudad moderna.

La formación superior de los ingenieros les preparaba para estos cometidos a partir de unos estudios que se reconocian como de un riguroso nivel científico. La calidad científica de los estudios era habitualmente reconocida en la época, valga como ejemplo el testimonio del dramaturgo y premio Nobel de literatura D. José de Echegaray, ingeniero a la sazón, que en 1897 decía "que en lo que pudiéramos llamar "regeneración matemática", la Escuela de Caminos ha tenido parte importantísima. Merced a su influjo, a la severidad de sus exámenes de ingreso y a la preferencia que siempre dio a los estudios matemáticos puros, formóse en pocos años un profesorado libre de matemáticas elementales" ${ }^{4}$.

En resumen la Escuela de Ingenieros de Caminos tenía desde sus orígenes una ideologia progresista, a la par que una disciplina castrense que podría atribuirse a que los primeros ingenieros de Caminos habían sido con anterioridad ingenieros militares ${ }^{5}$. Hay también que considerar en la formación de los ingenieros su proximidad con los ingenieros franceses salidos de la École Polytechnique y de la École Centrale des Arts

La polémica de competencias entre arquitectos e ingenieros está explicitada de manera or denada en el ya clásico libio de Bonet Correa. A., Miranda. F. y Lorenzo, S.: La polémica ingenieros-arquitectos en España. Sigio $x / x$ Colegio de Ingenieros de Caminos. Canales y Puertos y Ed. Turner, 1985.

EChegaray. José de: "La Escuela Especial de Ingenieros de Caminos, Canales y Puertos y las ciencias matemáticas:- Revista de Obras Públicas, $n^{\circ} 44$, tomo 1. 1897, pág. 2. Tomado del texto de José Manuel SANCHEZ RON: "Las ciencias fisico matemáticas en la España del siglo $x i x$ " en La ciencia en la España del siglo xix, ed. de José M. Lopez PIÑERo, Ayer, Madrid, 1992, págs. 72-73.

La idea es recogida por Arturo SofiA y Puig: lldefonso Cerdá, hacia una teoria general de la Urbanización. Colegio de Ingenieros de Caminos, Canales y Puertos y Ed. Turner, Madrid, 1979. pág. 51 
et Manufactures: franceses eran buena parte de los textos que utilizaban los estudiantes españoles de ingeniería ${ }^{6}$. El lenguaje arquitectónico y la funcionalidad de la arquitectura de los ingenieros, así como su formación, les convirtió en el instrumento perfecto en manos de la monarquía para crear la imagen de estabilidad y progreso que desde el poder se quería transmitir ${ }^{7}$. No tiene, pues, nada de extraño que las reformas urbanas y ensanches de ciudades en toda la Europa Occidental durante la segunda mitad del siglo $x \mid x$, fuesen llevadas a cabo en buena parte por ingenieros y bajo supuestos semejantes a los seguidos en España. De todos es conocida la preferencia del Barón Haussmann, artífice de la reforma de París durante el Segundo Imperio, por contar con una serie de técnicos especializados, ingenieros que poseian deseos de renovación, interés por los avances técnicos y sentido práctico, todo ello a disposición de los gobiernos que los demandaran para sus operaciones urbanísticas.

Hay que tener en cuenta que las labores de cartografía son la base para cualquier futuro proyecto de reforma urbana. La experiencia de los ingenieros militares en topografía y conocimiento cartográfico del territorio resultó muy útil para los ingenieros civiles en el plano de la urbanización. El Real Decreto de 25 de julio de 1846 por el que se legislaba sobre la obligatoriedad de levantar planos geométricos de las poblaciones, puso de manifiesto la incapacidad de algunos arquitectos para cumplir con este cometido por la falta de rigor de sus trabajos; caso notable es el de Juan Antonio Cuervo (1757-1834) encargado del plano de Madrid que tuvo que ser sustituido por los ingenieros Merlo, Rivera y Gutiérrez ${ }^{8}$. Esta demostrada aptitud produjo trabajos en serie como los del Capitán de ingenieros Joaquín Pérez de Rozas que levantó los planos de Albacete, León, Málaga y Valladolid ". No podemos olvidar el caso de Francisco Coello (18221898) Teniente de Ingenieros y fundador de la Real Sociedad Geográfica de Madrid, que colaboró con Pascual Madoz en los planos del Diccionario Geográfico-Estadistico-Histórico de España y sus posesiones de Ultramar, y que ocupó durante bastantes años la

SANChEz RON: Op.cit. pág. 73

A. CAmara Muñoz: Arquitectura e ingenieria en el reinado de Carlos III. Ayuntamiento de Madrid. Aula de Cultura. 1989. Esta idea es expuesta con respecto a los ingenieros del siglo xvIII. Juan Merlo era Ayudante en la Escuela de Ingenieros. En 1839 estaba como profesor de Arquitectura Civil y Dibujo. Junto con Rivera y Gutierrez fue encargado del plano de alineación y diseño de la Plaza de Oriente de Madrid una de las más representativas empresas urbanas del reinado de Isabel II.

He ananixo, Javier: Arquitectura en España, 1770-1900. Cátedra, Madrid, 1989, pág. 453. 
Dirección de Operaciones Topográfico-Catastrales de la Junta General de Estadística ${ }^{10}$.

\section{HACIA UNA NUEVA IDEA DE CIUDAD}

La ciudad antigua se habia ido configurando a través del tiempo. Con el correr de la historia en las estructuras urbanas de nuestras ciudades, en lo esencial de su morfología, quedaron reflejados los cambios culturales, sociales, religiosos y políticos: por ello las ciudades que llegan al siglo Xix son objetos históricos que pueden dar cuenta del pasado. Corroborando esta idea Giulio Carlo Argan considera la ciudad como una obra de arte que en el curso de su existencia ha sufrido modificaciones, alteraciones, añadidos, disminuciones y hasta verdaderas crisis destructivas ${ }^{11}$.

Con anterioridad y en esta misma línea Lewis Mumford ${ }^{12}$ había dicho que la ciudad favorece el arte porque es el arte mismo, porque es en sí misma un producto artístico; por tanto al cambiar el sistema general de producción lo que era un producto artístico se ha convertido en un producto industrial. Todas estas opiniones no tratan sino de reflejar el paso de la ciudad antigua a la ciudad industrial que se va a producir a lo largo del siglo XIX, la necesidad de intervenir en la ciudad sobre unas nuevas bases culturales y organizativas acordes con los tiempos.

Con el despegue de la revolución industrial, lo que había sido una transformación lenta de los núcleos urbanos, que el tiempo habia ido modelando, se trastoca en un proceso apresurado para hacer frente a factores que hasta entonces no habian hecho acto de presencia. Los más significativos son el aumento demográfico y la migración de la población rural a las ciudades, motivada por la necesidad de mano de obra en las industrias. Si Europa había duplicado sobradamente su población entre 1800 y 1900, España que a finales dol siglo XVIII tenía 12 millones de habitantes, alcanza los 18 y medio en 1900. El aumento de la población es más acentuado en ciudades como Madrid y Barcelona, que sólo entre 1880 y 1900 crecieron en más de 150.000 habitantes cada una con lo que rebasaron el medio millón en los comienzos del siglo xx.

QuiRos LINARES, Francisco: Las ciudades españolas en el siglo xix. Ámbito, Valladolid, 1991, pág. 15.

ARGian, G. C.: Historia del Arte como historia de la ciudad. Laia, Barcelona, 1984, págs. 73 y sigs.

Mumforo, Lewis: La cultura de las ciudades. EMECE, Buenos Aires, 1957 
Un rasgo característico en la evolución desde la ciudad antigua a la urbe industrial es el hecho de que a mayor desarrollo industrial mayores posibilidades de intervenciones urbanas de importancia. En España los cambios urbanos se producen con más lentitud, pues no será hasta la segunda mitad del siglo cuando comiencen a notarse los planes de reforma y los ensanches, que, como es natural, serán más notables en las zonas más evolucionadas industrialmente, caso de Asturias, las provincias vascas, Cataluña, y sobre todo Barcelona y Madrid.

La idea que entonces existe de ciudad moderna no deja lugar a dudas si revisamos los textos que tratan de acercarse al fenómeno de la urbanización. El arquitecto Mariano Belmás en un discurso leído el 4 de enero de 1887 al comenzar los debates de la Sociedad Española de Higiene considera la Urbanización una ciencia importantísima que entra de lleno en la esfera común y necesitada del concurso de todos los conocimientos especiales y generales ${ }^{13}$. Según Belmás las ciudades modernas derriban sus murallas ya sin función defensiva, ensanchan sus calles, mejoran la acometida de aguas y el alcantarillado, "se multiplican y mejoran las escuelas, hospitales, cuarteles, las iglesias y los teatros; se establecen los arbolados y parques", adelantos todos ellos que obligan irremisiblemente a un nuevo concepto de la urbanización moderna desde el punto de vista higiénico, dándole un sello característico especial que la distingue de la de otros tiempos.

\section{PROFESIONALES PARA LOS NUEVOS TIEMPOS}

Es un hecho que la urbanización de la ciudad moderna era una preocupación para todas las instancias implicadas pero sobre todo para el cuerpo de ingenieros civiles que fueron parte importante en el proceso de ensanche y saneamiento de las ciudades españolas. Una figura destacada a este respecto es Pablo de Alzola, uno de los ingenieros redactores del proyecto de ensanche de Bilbao y alcalde de esta población, quien en su libro Las obras públicas en España ${ }^{14}$, un verdadero manifiesto de la eficacia y profesionalidad de los ingenieros españoles, no duda en presentar los planes de ensanche de Barcelona, Madrid, Bilbao, San Sebastián o Gijón superiores a los sistemas empleados en las ciudades europeas ade-

\footnotetext{
13. BELMAS, Mariano: "La Urbanización». Anales de la Construcción y de la Industria, año XII, 1887, no 1 , págs. 8-13.

'4 Alzola, Pablo DE: Las Obras Públicas en España. Estudio Histórico. Imp. Casa de Misericordia, Bilbao, 1899
} 
más de considerarlos una organización genuinamente española. Pero en lo que Alzola no duda en calificar de empresa de "regeneración nacional» juegan un importante papel los ingenieros, según sus palabras «esa falange de soldados del progreso constituida por los Ingenieros del Cuerpo de Caminos consagrados al servicio del Estado, por regla general, con celo laudable y una rectitud que no han quebrantado, ni la plaga del caciquismo, ni los nuevos señores feudales de la política, que han desquiciado otros ramos de la Administración española» ${ }^{15}$.

La intervención de los ingenieros en la urbanización y su actuación como funcionarios civiles ha dado lugar a que se interprete el urbanismo decimonónico español como la aplicación de una fórmula única de ensanche institucionalizado y regulado, sin que se aprecie la existencia de una reflexión sobre la forma de planeamiento de la ciudad y del territorio ${ }^{16}$. Lo cierto es que tal debate o reflexión existió y que no tuvo un sólo punto de vista: no tenemos más que pensar en Ángel Fernández de los Ríos quien en 1868 cuando publicó El Futuro Madrid, en realidad estaba resumiendo el pensamiento de buena parte de su contexto cultural y político; su libro es tanto un estudio del estado de la ciudad de Madrid en esos años como de la posibilidad de planificar su expansión ilimitada sobre el territorio circundante ${ }^{17}$.

Otras publicaciones como la Revista de Obras Públicas, que aparece en 1853 y a la que podemos considerar el órgano de propaganda de los ingenieros civiles, o bien los Anales de la Construcción y de la Industria aparecida en 1876, recogen numerosas colaboraciones de ingenieros y arquitectos sobre temas de urbanización, que vienen a poner de manifiesto las transformaciones que ha provocado el crecimiento industrial y a las que es necesario dar respuesta con medidas avanzadas desde el punto de vista técnico ${ }^{18}$.

AlzOLA: Op. Cit. pág. 30.

Fernando DE TFRAN defiende esta teoría en Planeamiento urbano en la España contemporánea (1900-1980). Alianza, Madrid, 1982. Se apoya en las opiniones de Martín Bassois Coma. Génesis y evolución del derecho urbanistico espariol 1812-1956. Ed. Montecorvo, 1973). respecto a la diferencia de las primeras experiencias urbanisticas en España en relación a otros paises del entorno. ya que considera que se limitan casi exclusivamente a la expansión de las ciudades.

Feranandez de los Rios, Ángel: El Futuro Madrid. Los Libros de la Frontera, Barcelona, 1989. Con estudio introductorio de Antonio Bonet Correa "Ángel Fernández de los Rios y la génesis del urbanismo contemporáneo".

ISAC. Ángel: Eclecticismo y pensamiento arquitectónico en España. Discursos, revistas. congresos, 1846-1919. Diputación Provincial de Granada. Granada, 1987, pág. 203 y sigs. Es una clara exposición de las diferentes publicaciones sobre arquitectura y su papel en la formación del pensamiento arquitectónico y urbanístico. 


\section{LA GESTACIÓN DE UNA NUEVA TEORÍA URBANA}

Ha sido algo habitual considerar la primera mitad del siglo XIx la época en que España ha vivido de la teoría urbana procedente de las doctrinas ilustradas, para luego pasar invariablemente a los ensanches como ejemplo de la ciudad moderna o industrial. En el concepto académico de ciudad resalta el interés por los aspectos que tienen que ver con la salubridad y comodidad en las ciudades; así es general que se lleven a cabo o se perfeccionen completas redes de alcantarillado, iluminación, aprovisionamiento de aguas, empedrado de calles, limpieza, en resumen, todo aquello que pueda proporcionar unas condiciones de vida dignas. Además se hicieron habituales las zonas de esparcimiento como los bulevares arbolados que frecuentemente rodeaban los recintos amurallados y los parques o salones dedicados también al paseo. Era una idea comúnmente aceptada que fuera del centro ciudadano deberian quedar aquellos establecimientos peligrosos o incómodos, como los cementerios, hospitales, cárceles o cuarteles ${ }^{19}$.

Un personaje inquieto como Ramón de Mesonero Romanos, escritor y concejal del Ayuntamiento de Madrid, propuso en 1846 en un informe destinado al Ayuntamiento de la capital, la posibilidad de ampliar la ciudad por medio de "cinco grandes arrabales extramuros" que servirían de habitación cómoda para la mayoría de artesanos y gentes de escasos medios económicos; también en ellos habría lugar para las grandes fábricas y talleres que en el interior no hallasen edificios adecuados, además de acoger establecimientos peligrosos o incómodos que pudieran afear la población. Los arrabales podrían albergar los lugares de esparcimiento como bailes y paradores ${ }^{20}$.

Propuestas como estas evidencian las precarias condiciones de vida que se daban en las viejas ciudades. El aumento de su población había hecho que se encontraran con graves problemas de saneamiento, abastecimiento de aguas, hacinamiento en las viviendas que afectaba, sobre todo, a la creciente clase obrera que sobrevivía con bajos salarios, mal ali-

La teoría académica sobre la ciudad fue el tema de mi articulo: «Teoria urbana en la España de la primera mitad del siglo $x \mid x$ ” en Homenaje al Profesor Hernández Perera, Ed. Departamento de Historia del Arte II, Facultad de Geografia e Historia, Universidad Complutense, Madrid. 1992

20 Mesonero Romanos, Ramón de: “Proyecto de mejoras generales de Madrid presentado al Exmo. Ayuntamiento Constitucional» en El Antiguo Madrid. Paseos anecdóticos por las calies y casas de esta villa. 1864. Obras de D. Ramón de Mesonero Romanos, tomo IV, pág. 294. Biblioteca de Autores Españoles, Madrid, 1967. 
mentada y en condiciones de trabajo que rayaban con la esclavitud. La situación había generado un concepto antiurbano que veía la ciudad industrial como "un foco de pestilencia física y moral" y que contemplaba la idea del ensanche como una esperanza de renovación.

Es lógico que frente a esta situación surgieran voces precursoras adelantando una nueva teoría urbana, como la del ingeniero lldefonso Cerdá (1815-1876), quien salió en 1841 de la Escuela para integrarse en el Cuerpo de Ingenieros de Caminos al servicio del Gobierno. En los primeros años su trayectoria profesional se centra en proyectos de carreteras, conducciones de agua, tendidos telegráficos, canalizaciones para el riego etc., además de adquirir un claro conocimiento del territorio de Barcelona ${ }^{21}$.

Cuando en 1867 publicó Teoría general de la urbanización y aplicación de sus principios y doctrinas a la reforma y ensanche de Barcelona, no hizo sino compilar todos aquellos conceptos sobre la urbanización, «la materia de mayor importancia de cuantas pueden surgir en el seno de las sociedades", que había tratado de poner en práctica con su proyecto de reforma y ensanche que presentó al concurso que el Ayuntamiento barcelonés convocó en 1859.

Desde su consagración a los problemas urbanos, Cerdá incorporó un espíritu nuevo sobre el concepto de urbanización: la idea de que ésta debe ser científica, artística y hábilmente combinada ${ }^{22}$, sin respetar las tradicionales concepciones que ven a la ciudad como el resultado de la configuración caprichosa del tiempo. Es verdaderamente novedosa la metodología empleada para la urbanización, que inicia con una vasta recogida de datos estadísticos, antecedentes del problema y, sobre todo, el levantamiento de planos topográficos.

Tal y como Soria y Puig hace ver, en el siglo xix existían diferentes propuestas respecto a la ciudad: desde planteamientos utópicos a corrientes que deseaban la integración del campo y la ciudad, asi como concepciones muy técnicas que ofrecen una ciudad ideal desde el punto de vista de la higiene, del ferrocarril, de la vivienda o de la defensa militar ${ }^{23}$.

Magkinya, Francesc: "Cerdá, ingeniero de caminos» en Cerdá, Ciudad y Territorio. Una vi. sión de futuro. Electa, Barcelona, 1994, pág. 127.

2. CERDA, Ildefonso: Teoría General de la Urbanización y aplicación de sus principios y doctrinas a la reiorma y ensanche de Barcelona. Imprenta española. Madrid, 1867. Ed. Facsimil Instituto de Estudios Fiscales, Madrid, 1971, tomo I, pág. 622. El tomo 11 contiene un estudio sobre "La vida y obra de lldefonso Cerdá" por Fabián Estapé

SORIA y PUiG. Arturo: Ildefonso cerdá, hacia una teoria general de la urbanización. Col. de Ingenieros de Caminos, Canales y Puertos, Ed. Turner, Madrid, 1979, pág. 120. 


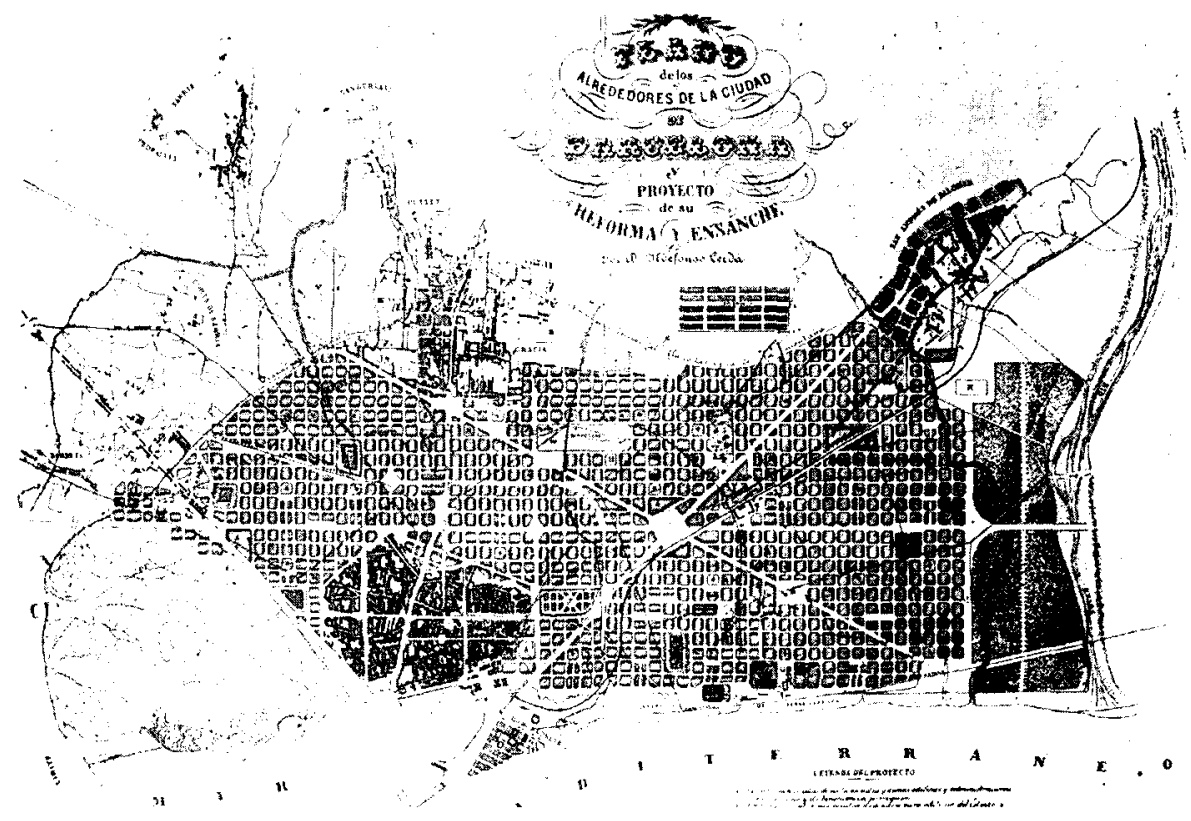

Ilustración 1: Plan Cerdá para Barcelona (1859).

Cerdá recoge muchas de estas ideas para proponer una nueva ciudad en la que todos los problemas puedan resolverse.

Llama la atención su fe en la ciencia como generadora de avance social e instrumento para la mejora de las condiciones de vida generales e individuales, algo muy habitual en el positivismo del siglo XIX; su confianza en la utilidad de los avances técnicos: «la condición que deben satisfacer todos los inventos de la edad presente es la de generalizarse y democratizarse" ${ }^{24}$.

Otra característica de su concepto urbanizador es la extensión ilimitada del ensanche, un sistema de urbanización que objetivamente no conoce límites y que se puede expandir a voluntad. "Rurizad lo urbano; urbanizad lo rural» ${ }^{25}$ es la máxima que no distingue entre campo y ciudad que se apoya en avances técnicos como el telégrafo o el ferrocarril que permiten la comunicación.

El tema de la higiene es otro de los aspectos que lidefonso Cerdá asimiló y que resume con este pensamiento: «A medida que va disminuyen- 
do la superficie urbana que toca por habitante, se va aumentando la mortalidad de la población» ${ }^{26}$. Sus palabras son la síntesis de las ideas higienistas entonces en boga que en Cataluña defendía Pedro Felipe Monlau, autor del conocido folleto iAbajo las murallas!, publicado en 1841, que proponía derribar el recinto murado de Barcelona. Monlau y los higienistas defendian la necesidad de bajar la densidad de las poblaciones apoyados en la creencia en los beneficios higiénicos que tenía para los habitantes, beneficios no sólo físicos, sino también morales, pues el hacinamiento propiciaba el descontento y el desorden social ${ }^{27}$. Cerdá comparte esta preocupación y analiza cuáles eran las necesidades sociales, económicas y de alimentación que se daban en Barcelona antes de que en 1854 se decretase derribar las murallas. Recopiló todos los datos en su Monografía Estadística de la clase obrera de Barcelona, de $1856{ }^{28}$. Para él la higiene pública ha de ser la base de la distribución de los edificios, la forma y dimensiones de las nuevas plazas, calles y manzanas, así como las obras subterráneas.

Un aspecto prioritario para el anteproyecto de ensanche de Barcelona que Cerdá llevará a cabo, fue la definición del espacio físico sobre el que se iba a actuar por medio del levantamiento de planos topográficos, tarea que realizó con absoluta minuciosidad en 1854, sustituyendo el trabajo anterior realizado por ingenieros militares; cubría una amplia área: desde el Besòs hasta la perpendicular al mar por detrás de Montjuïc, englobando el marco de crecimiento del término metropolitano a Barcelona y sus seis municipios circundantes ${ }^{29}$.

Con todos estos factores Cerdá redactó un proyecto de ensanche que no es sólo una propuesta formal y estética que pudiera dar lugar a una ciudad monumental desarrollada de manera concéntrica en torno al casco antiguo, sino que es el resultado del estudio y análisis racional de las condiciones que se daban en Barcelona. Cerdá llega a esta solución después de una tarea que podríamos llamar de campo: levantamiento de planos topográficos, estudio de las ordenanzas, de los posibles sistemas de fi-

\footnotetext{
CERdA: Op. cit., tomo II, pág. 543.

27 Esta doctrina está muy claramente recogida en el trabajo de Luis URTEAGA: "El pensamiento higienista y la ciudad: la obra de P.F. Monlau". Urbanismo e Historia Urbana en el mundo hispánico. II Simposio, 1982. Universidad Complutense, Madrid, 1985, tomo I, pág. 397-412.

28 Se publicó como apéndice el el volumen II de la Teoria General de la Urbanización, pero sirve como estadística y prólogo para el anteproyecto de ensanche de Barcelona.

29 TARRAGO, Salvador: "La evolución del intervias de Cerdá: tres propuestas $(1855,1859$ y 1863) para la fundación de una nueva ciudad industrial" en Cerdá. Ciudad y Territorio. Una visión de futuro. Electa, Barcelona, 1996.
} 
nanciación y de las diferentes tipologias arquitectónicas. Con todos estos datos trató de buscar una solución para la ciudad, que permitiera el pleno desarrollo del individuo, que sustituyera a las antiguas urbes hacinadas donde la humanidad encontraba "su tortura, su degeneración física y su aniquilamiento moral e intelectual».

El método seguido por Ildefonso Cerdá estableció unas reglas para el trazado y mejora de las poblaciones que fueron seguidas por otros ingenieros en distintos proyectos hasta el punto de hacer necesaria la promulgación de una ley de ensanches el 29 de Junio de 1864 basada en buena parte de sus teorías.

\section{ENSANCHES E INGENIEROS}

Desde la primera de 1864, las leyes de ensanche definen el carácter de la legislación y el pensamiento político-administrativo que existía sobre expansión de las ciudades; el objetivo básico es facilitar el crecimiento, más que ordenar la ciudad ${ }^{30}$. En todo los casos prima la idea de dar facilidades a la urbanización, incluso con incentivos fiscales a los promotores. No obstante todos los anteproyectos debían ajustarse a unas directrices muy similares al proyecto que lldefonso Cerdá realizó para Barcelona, aprobado por una Real Orden el 7 de Junio de 1959, o al de Madrid de Carlos María de Castro, aprobado por Real Decreto de 19 de Julio de 1860, pioneros y modelos para sucesivos ensanches.

Hay que observar, tal como Bassols indica, que las memorias explicativas de los proyectos evidencian un alto grado de madurez teórica en la ordenación urbanística de los ensanches. Aparece clara la ruptura con las reglas tradicionales; desde el punto de vista formal el ensanche rompe con la escala antigua para emplear una nueva unidad de medida, una malla que engloba las estructuras existentes y que puede extenderse a voluntad. Los ensanches, como exponentes de la nueva ciudad, son el resultado de proyectar la totalidad de la fábrica urbana como si de un único edificio se tratase y son la lógica consecuencia del nuevo crecimiento económico verdadero motor del desarrollo urbano ${ }^{31}$.

\footnotetext{
Bassols Coma: Op. cit. pág. 254

El concepto está recogido del trabajo de M. DE SOLA-MOrales: "Los ensanches: Hacia una definición". Arquitectura Bis, n¹3-14, 1976, pág. 44. Considera los ensanches algo caracteristico de los países mediterráneos $v$ consecuencia de su contexto social y económico.
} 
Ya sea el trazado en cuadrícula o la red concéntrica, se ajustan a los supuestos innovadores que se aplicarán en las ciudades renovadas o ensanchadas. Este nuevo concepto de la urbanización parece identificarse, o al menos se ha querido ver así, como obra de los ingenieros. La trama ortogonal se ha visto inspirada en modelos norteamericanos y en los trazados hispanos que pasaron a América para la construcción de nuevas ciudades, modelo que pareció regresar con las estructuras regulares de las ciudades españolas de la Ilustración (La Carolina, La Carlota, Águilas, etc.) ${ }^{32}$. También la teoría urbana del Renacimiento parece haberse convertido en tradición en los proyectos de ensanche.

La aportación de Cerdá y lo que hace diferente su proyecto para Barcelona es la posibilidad de intervenir de manera científica en la ciudad; ello suponía una novedad pues incluso Rovira y Trías, su rival en el concurso de Barcelona, creía que "el trazado de una ciudad es obra del tiempo más que de la arquitectura".

Cerdá diseñó una extensa trama cuadrangular que engloba la vieja Barcelona, los pueblos inmediatos de Gracia y San Andrés de Palomar y la montaña de Montjuic hasta el río Besòs. Una sucesión de calles paralelas al mar, son cruzadas por otras en sentido vertical dando lugar a manzanas cuadradas. Dos vías diagonales, de $50 \mathrm{~m}$. de anchura atraviesan el conjunto: las Corts y Aragón. También la Meridiana y el Paseo de Gracia tienen $50 \mathrm{~m}$. al igual que Marqués de Duero y Paralelo. Tres vías de $20 \mathrm{~m}$. enlazan con la antigua ciudad: Campo Sagrado-Pallars, Muntaner y Claris. Las manzanas son cuadradas pero con los ángulos achaflanados, de manera que en los cruces y nudos se forman plazas. Las manzanas son siempre abiertas, sólo construidas en dos o tres de sus lados, de manera que el interior se ocupe con huertos o jardines.

En todo el trazado hay espacios para zonas verdes, iglesias, edificios públicos, hospitales y cementerios. Un gran bosque haría de frontera con el río Besòs. Estaba previsto el itinerario de los tendidos ferroviarios y de las canalizaciones de agua ${ }^{33}$. Todo el proyecto está planteado en virtud del concepto de higiene y circulación (higienismo y movilidad) en palabras de Cerdá.

Esta tipología urbana tuvo muchos detractores; la uniformidad del trazado, la nuclearización de los barrios con sus servicios y equipamientos,

CAPEI, Horacio: Capitalismo y morfologia urbana en España. Los Libros de la Frontera, Barcelona, 1983, pág. 35.

Tarrago, Salvador: "La evolución del intervías de Cerdá: tres propuestas (1855, 1859 y 1863) para la fundación de una nueva ciudad industrial’, en Cerdá, Ciudad y Territorio. pág. 67. 
produjo malestar entre los que lo interpretaron como un atentado contra "los intereses creados". Ruperto Lacosta, miembro destacado del ayuntamiento barcelonés y partidario del proyecto Rovira, creía que ocasionaría "perjuicios económicos de consideración» y estaría en contra del "orden lógico y natural de distribución de las diferentes clases del pueblo barcelonés"; también critica la ruptura con el concepto de centro urbano "esta centralización que hallamos en todas partes, siendo la única causa del orden y de la prosperidad, es la que queremos ver establecida en el sistema de distribución de un gran pueblo» ${ }^{34}$.

Lacosta no es el único que pensaba así, puesto que la idea de núcleo central en la ciudad y de jerarquización en su trazado está en la base de muchos de los proyectos de ensanche. El de Madrid del ingeniero Carlos $M^{a}$ de Castro, aprobado por R. D. el 19 de julio de 1860 , es una estructura yuxtapuesta a la ciudad antigua, sin soluciones para el tránsito de la nueva población; eso sí reitera el trazado en damero, pero respetando el núcleo ciudadano antiguo y distribuyendo de manera jerárquica en los distintos barrios a las diferentes clases sociales: los barrios residenciales y aristocráticos estarían a ambos lados de la Castellana, las clases medias en los barrios de Salamanca y Argüelles, Chamberí sería un barrio fabril y los barrios obreros estarían en el sur de la calle de Alcalá y detrás del Retiro, designando la zona de Embajadores y Puente de Toledo para asentar la industria y reservando las riberas del Manzanares como zonas agrícolas ${ }^{35}$.

Un planteamiento similar, salvando las lógicas diferencias topográficas, tiene el ensanche del arquitecto Antonio de Cortázar (1823-1884) para San Sebastián, de $1864^{36}$; con algunas modificaciones posteriores, el ensanche de San Sebastián se transformó en una nueva ciudad, en la que estaban contempladas la alameda o salón, el bulevar, la plaza porticada y la iglesia, rodeada asimismo de una plaza con soportales. En resumen una nueva ciudad junto a la antigua.

Bilbao, población con una industria floreciente y una burguesía en expansión, planteó proyectos de ensanche con muchos rasgos cerdianos y

\footnotetext{
34 Ruperto Lacosta: Paralelo entre el proyecto de ensanche de Barcelona de D. Antonio Rovira y Trias, premiado por la junta calificadora del certamen abierto por el Exmo. Ayuntamiento y el proyecto de D. Ildefonso Cerdá expuesto en el concurso. Imp. de Luis Tasso, Barcelona, 1859. Reproducido por F. Estapé en Teoria General de la Urbanización, 1971, tomo III, pág. 489 510 y citado por Soria y PUIG: Op. cit., pág. 130.

35 Plan Castro. Estudio preliminar de Antonio Bonet Correa. Colegio Oficial de Arquitectos de Madrid, Madrid, 1978.

36 La exposición del proceso de ensanche en Rooriguez Soronda, M. C.: Arquitectura Pública en la ciudad de San Sebastián (1813-1922). San Sebastián, 1985.
} 
una actitud propia de los ingenieros civiles que, si recordamos las palabras de Pablo de Alzola ${ }^{37}$, están realizados con sujeción a planos previamente estudiados.

El primer proyecto había sido encargado al ingeniero Amado Lázaro y se ajustaba a lo dispuesto en la ley de 7 de Abril de 1861 por la que el Gobierno autorizaba a extender los límites jurisdiccionales de la villa de Bilbao. La necesidad del ensanche procedía de la situación de hacinamiento y falta de espacios, 10 mismo de vivienda que de ubicación de almacenes y talleres, que se daban en el viejo Bilbao.

A partir de estas premisas, Lázaro aplica una concreta metodología para diseñar un ensanche de manera que a cada habitante le correspondiese una superficie de $40 \mathrm{~m}^{2}$ y que fuese suficiente en un plazo de 150 años. Las mayoría de las calles tendrían una anchura de $20 \mathrm{~m}$ aunque habría algunas mayores, igual altura correspondería a los edificios que las cierran. El Bilbao de Lázaro es, en realidad, una nueva ciudad ubicada al otro lado del río Nervión,

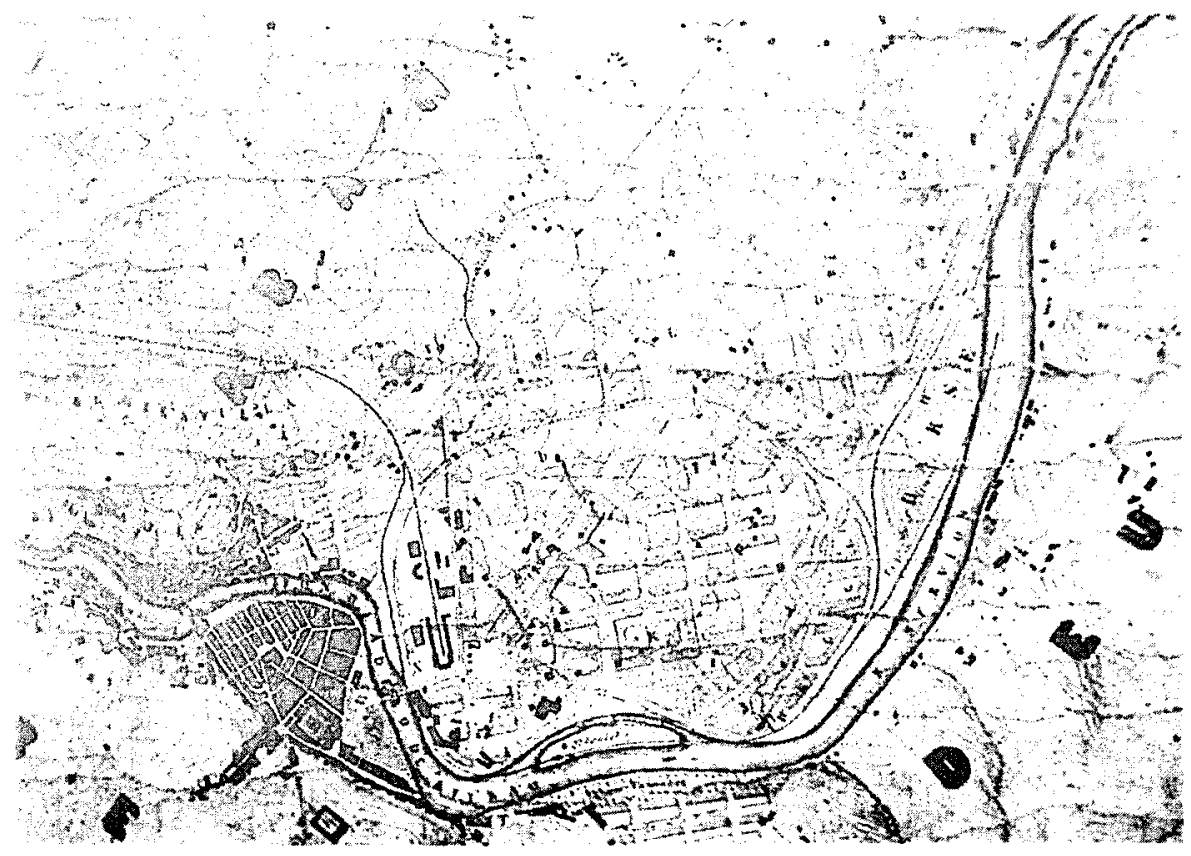

llustración 2: Proyecto de Amado Lázaro para Bilbao (1861).

AlzOLA: Op. cit. pág. 30 
que ocupa 229 ha. de la anteiglesia de Abando. Comenzó por levantar un plano topográfico del terreno a urbanizar, además de reunir una serie de datos estadísticos que revelaran las necesidades de la ciudad de Bilbao ${ }^{38}$.

El ingeniero Lázaro diseñó un plano con una organización central alrededor de una gran plaza, en la que se cruzarían la arteria principal de 50 $m$ que conduce a la estación ferroviaria, con otra en sentido perpendicular de igual anchura. Estas dos vías, orientadas en sentido norte-sur y esteoeste, centran un trazado en damero, con manzanas achaflanadas que pueden estar construidas en dos o tres de sus lados, para facilitar la ventilación y protegerse de los vientos. No olvidó situar en el exterior hospital, matadero, lavadero, jardines, plazas, mercado, aduana y cementerio.

El proyecto fue rechazado en las sucesivas instancias administrativas, ante la supuesta imposibilidad de llevarlo a cabo por los costes que implicaban las expropiaciones en los terrenos de Abando.

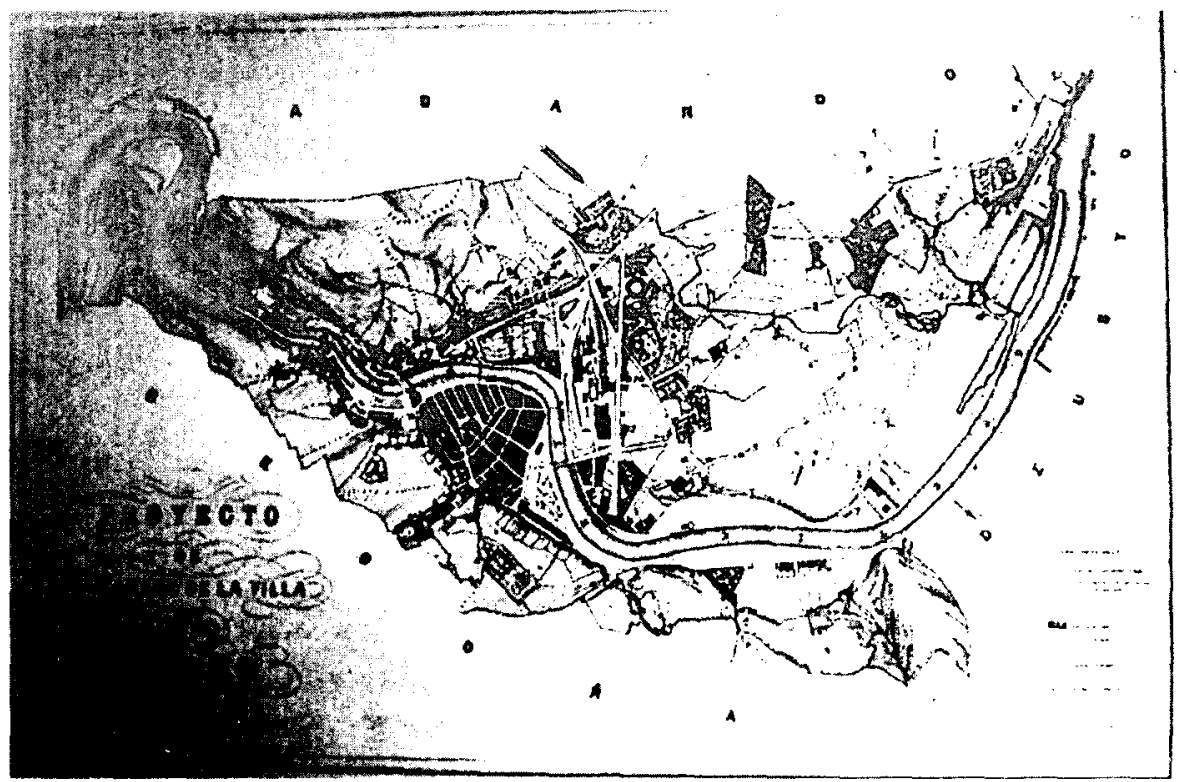

Ilustración 3: Proyecto de ensanches para Bilbao de Alzola, Achúcarro y Hoffmeyer (1876).

38. El proyecto de Amado Lázaro se ha publicado en: Memoria descriptiva sobre el proyecto de ensanche de la Villa de Bilbao. Reproducción facsimil del texto original de 1862 . Servicio Ceritral de Publicaciones del Gobierno Vasco, Vitoria, 1988. Un interesante análisis se recoge en el trabajo de Ramón LosadA RodrigueZ: “El Plano de Ámado Lázaro: Notas para una aproximación a los antecedentes del Ensanche bilbaino". Ciudad y Territorio, julio-septiembre, 1984, n 61, pág. 5 . 
La ley de ensanches de 1864 cambió el marco de relaciones que habían hecho imposible el plan de Lázaro que se convirtió en el antecedente y la memoria para el siguiente proyecto redactado en 1873 por los ingenieros Pablo Alzola y Ernesto Hoffmeyer junto con el arquitecto Severiano Achúcarro, que fue aprobado por Real Decreto el 30 de Mayo de $1876{ }^{39}$.

Aunque apoyados en la propuesta de Lázaro y respetando el emplazamiento, el proyecto de 1876 procura una más fácil y rápida comunicación de los nuevos barrios entre sí, con la ciudad antigua y con los centros de transporte y de comunicación. Se desea que las calles sean lo más largas y rectas posibles, interrumpidas solamente por algunas plazas que atenúen la monotonía producida por las líneas paralelas que forman las fachadas de las casas, calles siempre bien orientas respecto a los vientos. Las manzanas deben tener dimensiones convenientes para que resulte una relación aceptable entre la superficie edificada y la destinada a patios y jardines. Se

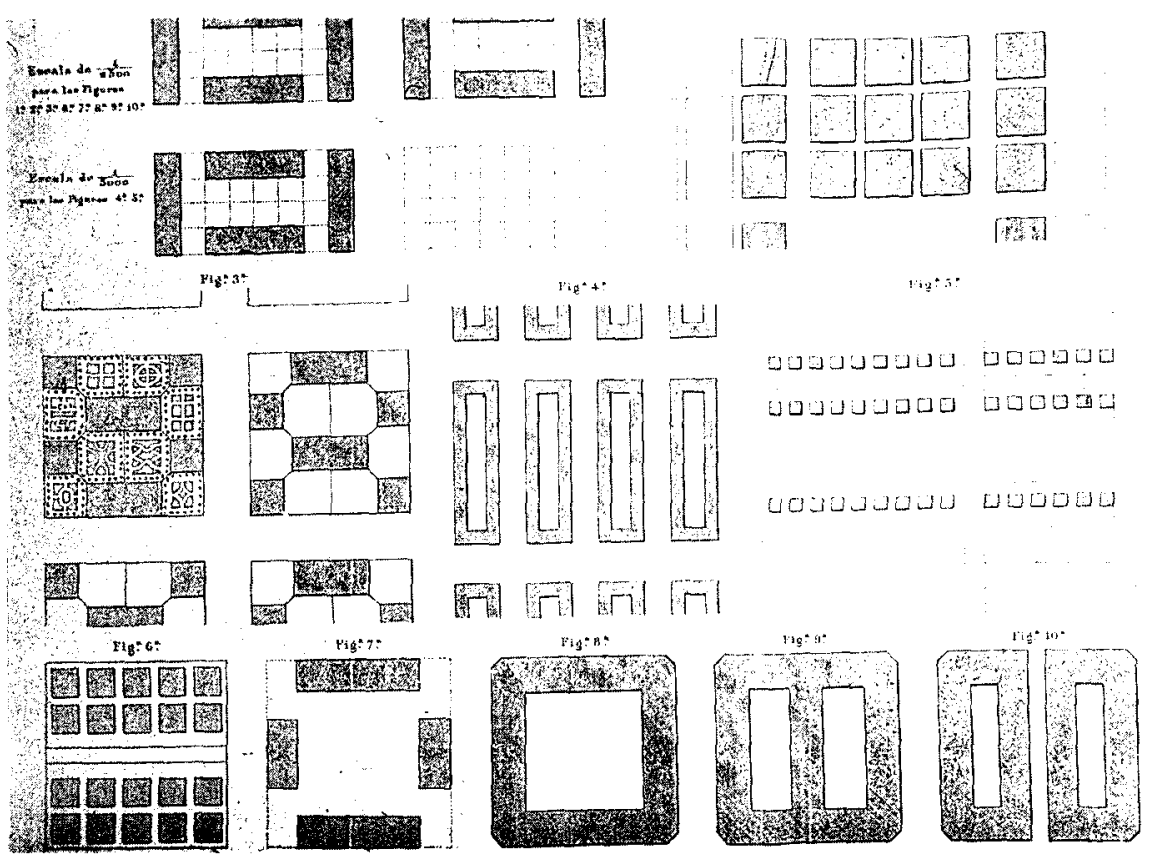

Ilustración 4: Diferentes tipos de manzanas. Memoria del Proyecto de ensanche de Alzola para Bilbao (Litografía de Denon).

35 Memoria del proyecto de ensanche de la villa de Bilbao de 1876. publicado en Anales de Obras Públicas, tomo $5, n^{\circ} 6$. Existe una edición facsimil publicada por el Colegio Oficial de Aparejadores y Arquitectos Técnicos de Vizcaya en 1988 
piensa en destinar a paseos y parques aquellas zonas del terreno que por sus accidentes no se prestaran a una regular edificación, que serían adecuadas para trazar jardines pintorescos.

La estructura del ensanche está dominada por la Gran Vía de San Mamés de $26 \mathrm{~m}$ de anchura, que parte de una gran plaza circular y atraviesa el conjunto. Casi en el centro se ha proyectado una plaza elíptica (140 x110 m.) donde se cruzaría el movimiento de las principales vías de la ciudad. Existen en el plano otras plazas secundarias, de diferentes formas, incluso una porticada indicada para los días lluviosos. Como en el proyecto Cerdá, los encuentros de calles dan lugar a plazoletas, achaflanando las manzanas para facilitar la circulación. En conjunto el proyecto ha mezclado la reticula uniforme con diagonales y perspectivas que producen gran variedad de formas y situaciones en el plano.

Otro ensanche con organización circular en torno a una plaza elíptica se propuso también en la ciudad de Gijón; la plaza de Evaristo San Miguel sirve de centro a una estructura radial. De ella salen ocho calles que dan lugar a manzanas de planta trapezoidal; la anchura de las calles es de 11,5 $\mathrm{m}$ excepto la principal y eje del ensanche, Uría, que tiene $14 \mathrm{~m}$. En el resto se respeta la trama ortogonal. El Plano de ensanche de la población de

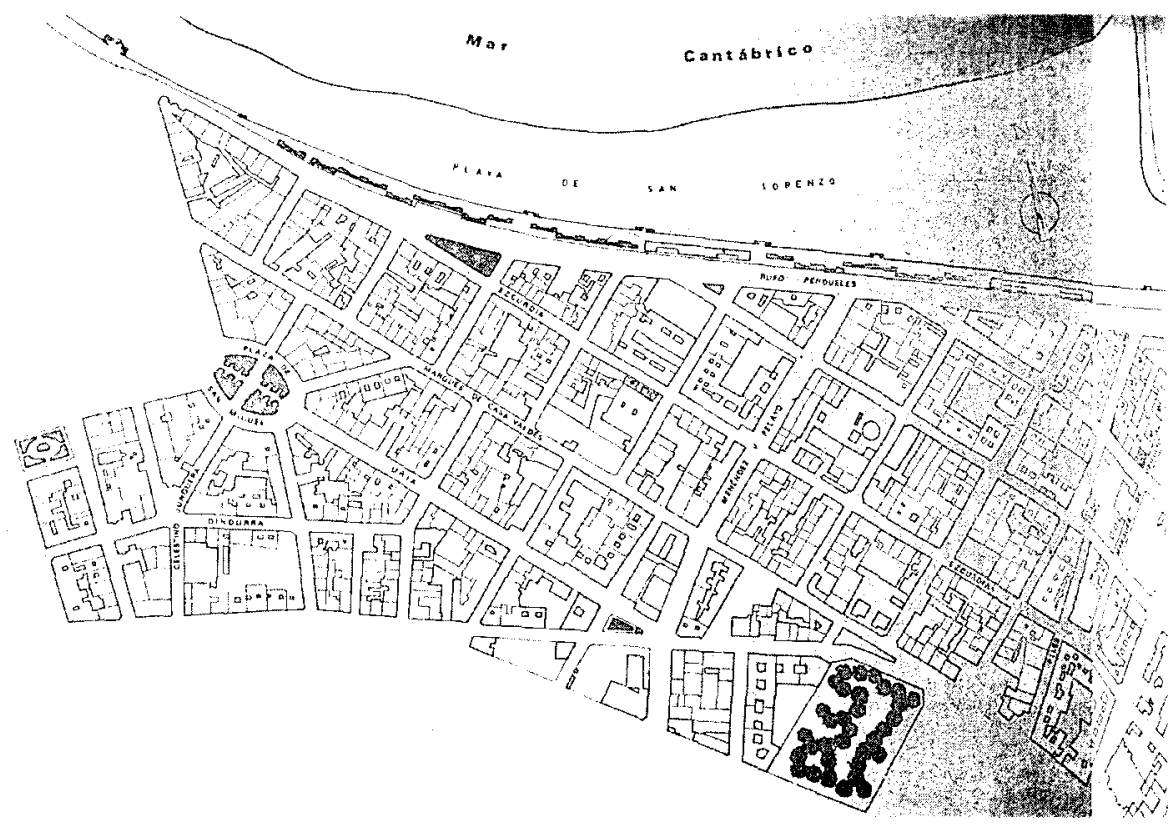

Ilustración 5: Gijón, ensanche del Arenal. 
Gijón por el Arenal de San Lorenzo se aprobó en 1867, si bien fue actualizado por su autor el arquitecto Lucas $\mathrm{M}^{a}$ Palacio con la colaboración del Capitán de Ingenieros García de los Ríos. El proyecto respondia a la necesidad de Gijón de ampliar sus límites, con una población hacinada dentro del recinto amurallado propio de su calidad de plaza fuerte, categoría que perdió en $1868{ }^{40}$.

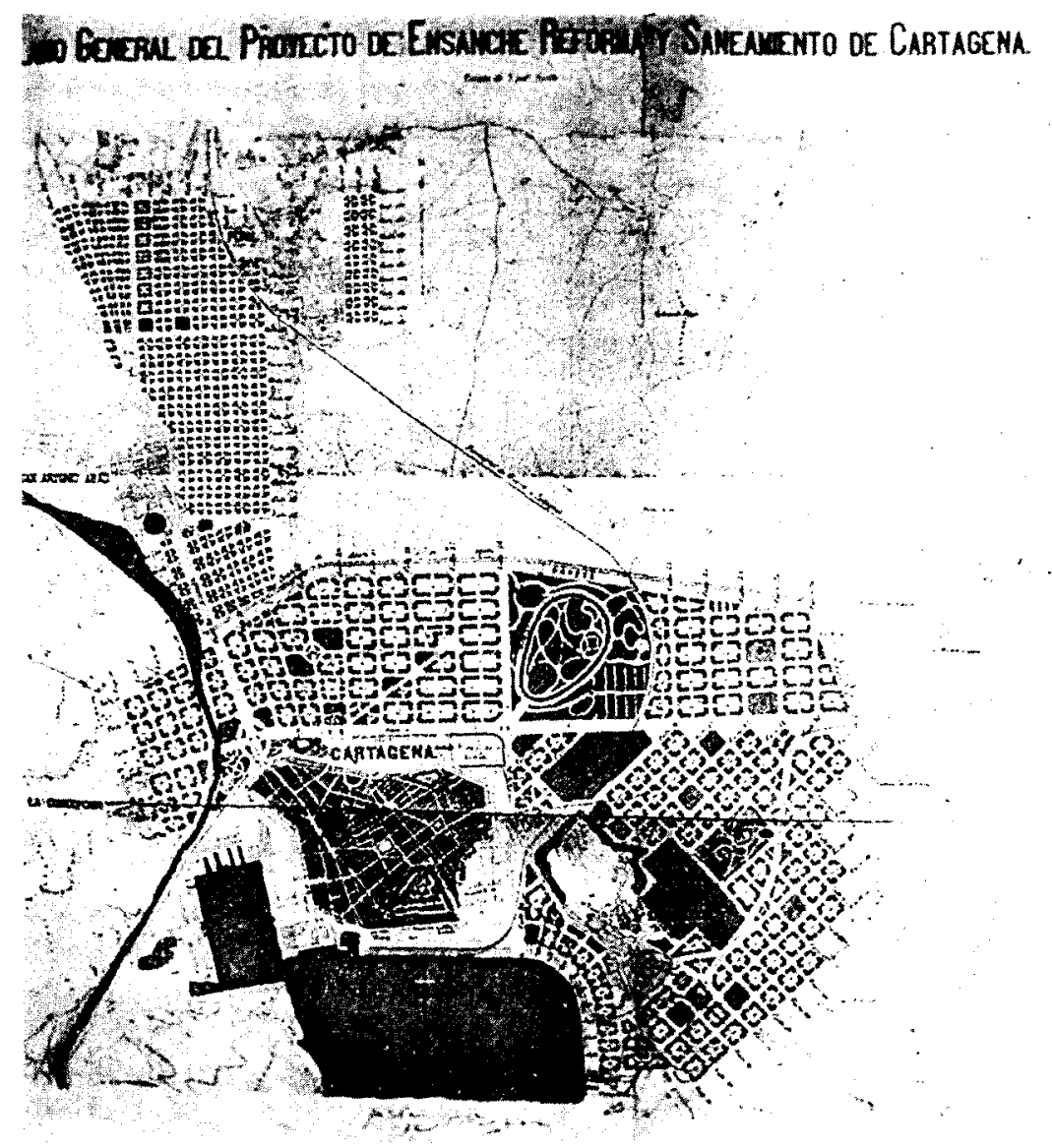

Ilustración 6: Plano del proyecto de ensanche para Cartagena.

40 El trabajo más importante sobre Gijón es el de Ramón ALvARGOnZALEZ: Gijón: Industrialización y crecimiento urbano. Gijón, 1977. También un sucinto resumen del mismo autor en "Las ciudades industriales portuarias: Gijón y Avilés" en Geografía de Asturias, tomo 2. Ayalga Ed., Salinas (Asturias), 1982. 
En años sucesivos se fueron aprobando diferentes proyectos de ensanche (Pamplona en 1881, Zaragoza en 1894, Palma de Mallorca en 1901) incluso el de Cartagena de 1897 que se aprobó en 1900.

El proyecto de Cartagena, bastante tardío y que no se concluyó, recoge muchas de las características de la teoría cerdiana, desde la comunicación interviaria a la misma idea de urbanización expansiva; incluso emplea el modelo de manzana abierta que permite la circulación del aire ${ }^{41}$. Su misma orientación, de ruptura con el corsé fortificado de Cartagena, y la idea de contribuir a la regeneración urbana de la ciudad, convierten a este proyecto en una prueba más para el conocimiento de una metodología urbanizadora que los ingenieros civiles pusieron en marcha y que refleja el paso hacia la ciudad industrial.

A pesar de las mejoras que para las ciudades suponían estos proyectos, en su mayor parte fueron modificados, siempre en busca de aumentar los beneficios económicos. Éste también fue el motivo de que muchos apenas se iniciasen: los intereses económicos que les hicieron nacer, en buena medida fueron la causa de su paralización.

Sobre el particular el libro de Javier PthEz RC.IAS: Cartagena 1874-1936 (Transformación urbana y arquitectura. Ed. Regional de Murcia, Murcia, 1986. 